\title{
The Application of Multi-modal Discourse Analysis Theory in College English Reading Education
}

\author{
Kou Li \\ Xijing University, Xi’an, Shaanxi, 710000
}

Keywords: Modal Discourse, English Reading, Multi-modal Discourse

\begin{abstract}
The application of modal discourse analysis in college English teaching practice can improve the quality and efficiency of college English teaching through the multi - modal multi channel communication. The construction of multimodal teaching resources, the cultivation of multimodal reading ability and the multimodal application ability of teachers are the important application strategies of multimodal discourse analysis theory in college English teaching.
\end{abstract}

\section{Introduction}

English reading ability is an important skill of college students. To cultivate this skill, colleges and universities will read the class as an important part of college English teaching. However, the current college English reading class teaching effect is still unsatisfactory: students read the speed of the general slow, answer the accuracy rate is low, to participate in the English grade examination to read part of the lost more. The main reason is that the classroom boring, students learning interest is not high. How to fully mobilize the students 'reading interest in the limited classroom time and improve the students' reading ability is the urgent problem to be solved in the current college English reading teaching. The emerging multi - modal discourse analysis theory provides a new idea for the reform of college English reading teaching. Multimodal discourse analysis emphasizes that interpersonal communication should not be limited to language factors, but should be widely used in a variety of media, such as images, music, gestures and so on. The essence of classroom teaching is the communication between teachers and students, and the multi - modal discourse analysis theory is used to guide English reading. It can stimulate students' ability of multiple reading and achieve the same effect.

\section{Multimodal Discourse Analysis Theory}

Multi-modal discourse analysis theory emerged in the mid-90s of the 20th century, it was able to be born and widely concerned, mainly due to two aspects: First, the deep development of discourse analysis theory, the second is the modern scientific and technological progress. The theory of multimodal discourse analysis is based on Halliday 's system functional linguistics. Systemic functional linguistics holds that language is a social symbolic system, or a system of meaning. In addition to language, painting, sculpture, music, dance, etc. can also be regarded as the meaning of the system, they together with the language to achieve the symbol of the social significance of the function. Under the hallucination of Halliday's functional linguistics, scholars put forward the viewpoints of many multimodal discourse analyzes in the light of the development of modern science and technology. Among them, the most representative of the international research for the works of Kress and van Leeu wen Multimodal Discourse: the Modes and Media of Contemporary Communication. In this book, Kress and van Leeuwen argue that "multimodal refers to the use of symbolic moduli and their integration in the design of symbolic or symbolic events." [3] According to their point of view, All the channels and media, such as sound, action, gestures, images and so on. Discourse communication is not limited to language factors, but may also use various nonverbal factors. In addition, Kress and van Leeuwen also point out that the multidimensional nature of discourse is an important feature of the various discourse used in today's world of communication. 
Domestic scholars also have a wealth of research on multimodal discourse analysis theory. At the earliest introduction of multimodal discourse theory in China, Li Zhanzi, she published in 2003 published "multi-mode discourse social semiotics analysis" to discuss the multi-modal discourse analysis of social semiotics analysis of English teaching an important role. In the next few years, the study of multimodal discourse is generally sprout, which is representative of the "multimedia, multimodal learning analysis" published by Gu Yueguo in 2006, published by $\mathrm{Hu}$ Zhuanglin in 2007 "Multi-modalization in the study of social semiotics", Zhu Yongsheng published the "multi-modalization and analysis of the theoretical basis and research methods", 2009 Zhang Delu's "multi-modal discourse analysis theory and media technology in foreign language teaching The application "and so on. These studies or from the theoretical point of view of the multi-modal discourse analysis theory (Hu Zhuanglin, Zhu Yongsheng), or on the basis of theoretical research to build their own multi-modal discourse analysis framework (Gu Yue Guo, Zhang Delu). There are many new research topics on multimodalization, but for domestic college English reading teaching, few scholars have studied from the perspective of multimodal discourse analysis theory. Based on this, this paper attempts to explore the method of applying multimodal discourse analysis to college English reading teaching.

The application of multimodal discourse analysis in college English teaching can not only expand the amount of information in English classroom, but also enrich the students 'language practice and improve the students' ability to use language. We should focus on cultivating students 'multimodal reading ability. First of all, teachers can use a variety of auditory modal symbols to consciously develop students' multi-modal reading ability, according to the characteristics of students to design specific teaching activities. Such as film dubbing, short play, debates, and so on. You can also use the rest of the time, to the students to play some of the textbooks related to the classic English songs or students to introduce some classic English movies; Second, both teachers and students to mobilize a variety of senses, especially visual images, gestures, gestures Eyes, nods, facial expressions and other non-verbal symbolic meaning of the building. For example, in the PPT display, the teacher's body language is also very important. In addition to the auditory modality and visual modality, you can also try to use the sense of smell, taste, touch and other modalities. In addition to the auditory modal and visual modality, you can try to use the sense of smell, taste, touch and other modal. For example, students can sense the aroma of flowers, the taste of coffee through the sense of smell and taste sensation, and teach the classroom content better, but also make the English class more vivid and interesting. Multi-modal English classroom teaching can use a variety of teaching methods.

\section{College English Reading in Multi - modal Discourse Analysis Theory}

According to the description of Kress and van Leeuwen, multimodal discourse analysis theory requires the simultaneous use of multiple information carriers in communication. In the English teaching activities, the appropriate use of a variety of modalities, to fully mobilize the various senses of students, optimize English teaching. At the same time, the rapid development of modern multimedia technology for multi-modal teaching provides a convenient, teachers can more easily use the network resources for multi-modal teaching. In the following, the author will discuss how to use the multi - modal discourse analysis theory to carry out the teaching effectively in the introduction of the topic of college English reading class, the concept and the theory explanation and the text analysis process.

Now, before the reading class learning text, the introduction of certain topics has become the practice of many college English teachers, this method is similar to the warm-up exercise in physical exercise, help in a short time to quickly seize the attention of students, help Students review their previous knowledge of related topics and stimulate students' interest in learning. However, if the teacher in the introduction of some just boring to explain, then the introduction of the effect will undoubtedly be greatly reduced. Therefore, it is extremely important to make full use of multimodal discourse analysis theory in the introduction of the classroom. Only by using the theory of multi-modal discourse analysis can the part introduce the effect. The fourth "foreign 
teacher social cup" national college foreign language teaching competition (college English group) second prize works "Are We Raising a Generation of Spoiled Brats?" (Wang Lili) is very successful in the reading class topic introduction part of the use of more Modal discourse analysis theory.

In the process of reading and appreciation of the students in the process of teaching and appreciation of the students, the text covers the concept of "othering" ("othering"). To explain this more complex and boring concept, Zhang Xuelian teacher to show students three cartoon map, through the cartoon map bird dialogue, students can understand the "other" concept connotation. But if only the use of visual mode, so that students can watch their own pictures, then the teaching effect may not be very satisfactory. Therefore, in the course of teaching, Zhang Xuelian teachers make full use of voice and tone, vividly to the cartoon birds dubbing, vividly to the story of the way to analyze the "other" concept, the boring concept to explain the vivid specific, Help to deepen the understanding of students, memory. In addition, in the teaching of Zhang Xuelian teacher, she also used a wealth of eyes, action mode; lectures throughout the process, her voice and tone also with the content of the ups and downs. In the micro-class works, Zhang Xuelian teacher in the gestures, eyes, pictures and voice intonation are used to grasp the very place, multi-modal use of the poem to deal with this difficult reading text. Thus, in the teaching of English reading, especially to explain some of the more complex concepts, theory, make full use of multi-modal discourse analysis theory can achieve the abstract as a concrete effect.

\section{The Application of Multi - modal Discourse Theory in College English Reading Teaching}

In the analysis of the length of the sentence often need to explain in detail the types of sentences and subordinate between the subordinate relationship and the "multi-modal discourse" point of view, you can use the specific punctuation and printing to distinguish and positioning. Such as: the fourth edition of the Diagnostic and Statistical Manual of Mental Disorders says "pathological gam-bling" by the persistent, recurring and uncontrollable pursuit of less of money than of the thrill of taking risks in quest of a windfall. They have more feelings on this issue. In this case, will also encourage students to cherish the university life, more hard to learn. Because they realize that only then, they can thank and repay their parents have been selfless to pay, and our education will really do the "wake up" mind and personality purposes. From the teaching of the contents of the teaching materials, it is very feasible for the teachers to carry out the emotional teaching in time and in the teaching of the subject, and the successful emotional education will Teaching to promote the role. However, due to the traditional teaching methods and examination-oriented education, college life has just begun, most freshman self-learning awareness is not enough, independent learning ability is not strong, even if some students are very strong sense of learning, the results are also very good, However, if the neglect of their other aspects of the cultivation and training, then these students can only be qualified after graduation of intellectual, German hanging Branch, and even some students will lose their way after graduation. Also, most college students are the only child, parents for their growth and development to pay a lot, but most students think that is a matter of course, they do not really understand and understand their parents. Therefore, in the normal teaching at the same time timely emotional education is very important. Teachers need to guide and help from all aspects, to mobilize the enthusiasm and initiative of students to stimulate their interest in learning to help students form and maintain a lasting learning motivation, so that they take the initiative to participate in teaching. Teachers in imparting knowledge at the same time, but also pay attention to educating people, we must always bear in mind the "hundred years of tree" noble duties.

\section{Conclusion}

College English reading class text involves a wide range of reading a larger amount of students prone to fatigue. Therefore, teachers should take the students as the main body, in the introduction of reading part of the topic, the concept and theory to explain the link, the text analysis process to make full use of voice intonation, pictures, video, gestures, music and other modalities to carry out teaching, Strengthen the teaching effect, improve the students 'English reading ability, lay the 
foundation for the improvement of the students' comprehensive quality. It is foreseeable that the multimodal discourse analysis theory will play a greater role in the wider use of college English reading teaching in the future.

\section{References}

[1] Ma Li. The Construction of Multi - modal Reading Ability in College English Reading Teaching [J].Journal of Hubei Institute of Science and Technology. 2015 (11)

[2] Lu Meijia, Mu Jiao. A Study on the Influence of Multi-modal Teaching Mode on College Students' English Reading Ability [J]. China Electro-technical Education. 2014 (12)

[3] Yu Huanhuan. Multimodal discourse analysis theory in college English reading teaching application [J]. Journal of Lanzhou College of Education. 2015 (05)

[4] Liu Zhongcai. Journal of Heilongjiang College of Education (Social Science Edition) Journal of Heilongjiang Institute of Education (Social Science Edition)

[5] Zhang Delu, Ding Zhaofen. Foreign language teaching multi-modal selection framework [J]. Foreign language. 2013 (03)

[6] Xu Jun, Xia Rong. Empirical Study on Multimodal Design of Business English Writing [J]. Foreign Language. 2013 (04) 